\title{
Management Cycles: Their Concept, Essence and Role in Modern Economy
}

\author{
Igor K. Musayelyan ${ }^{1}$, Alexander V. Raychenko ${ }^{2}$, Gabdeliahat R. Latfullin ${ }^{2}$, \\ Valeriy V. Maslennikov ${ }^{3}$, Alexander N. Horin ${ }^{4}$ \\ ${ }^{1}$ Russian Presidential Academy of National Economy and Public Administration, Moscow, Russia \\ ${ }^{2}$ Institute of Public Administration and Law, State University of Management, Department of Management \\ Theory, 99 Ryazanskiy prospect, Moscow, 109542, Russia \\ ${ }^{3}$ Plekhanov Russian University of Economics, Department of Management and Business Technologies, \\ 36 Stremyanny per., Moscow, 117997, Russia \\ ${ }^{4}$ Lomonosov Moscow State University, Faculty of Economics, Department of Accounting, Analysis and \\ Audit, GSP-1, 1-46 Leninskiye Gory, Moscow, 119991, Russia
}

\begin{abstract}
The purpose of the present article is to research the variety of problems that determine managerial activity in terms of theory and practice. The research methods used by the author include scientific abstraction, comparative analysis, synthesis, generalization of theoretical conclusions, as well as the principles of integrated approach and consistency. The key practical impact of the research can be formulated as follows: it can be used in further theoretical studies of the nature and role of management cycles, as well as applied in management and business (in particular, in the process of managing enterprises, organizations, and companies).
\end{abstract}

Keywords - management cycle, decisions, trends, business processes, quality

\section{Introduction}

The peculiarities of the universal process format within elaboration and execution of management manifest themselves in the procedure-based notion of management cycles as a targeted impact in the format of construction causally determined sequence. Here

DOI: $10.18421 /$ TEM92-27

https://dx.doi.org/10.18421/TEM92-27

Corresponding author: Igor K. Musayelyan,

Russian Presidential Academy of National Economy and Public Administration, Moscow, Russia

Email: musayelyan.igor@rambler.ru

Received: 16 February 2020.

Revised: 11 April 2020.

Accepted: 20 April 2020.

Published: 27 May 2020.

(c) BY-NC-ND (C) 2020 Igor K. Musayelyan at al; published by UIKTEN. This work is licensed under the Creative Commons Attribution-NonCommercial-NoDerivs 3.0 License.

The article is published with Open Access at www.temjournal.com lies its difference from the systems approach, which, as a rule, exposes a permanently obsolescent performance of the discrete state of an object. In this regard, almost the entire range of modifications regarding the process approach increasingly needs research and development of engineering, as well as optimization of management cycles.

This, in turn, places appropriate demands on the development and adaptation of tools for applying the process-based approach, ensuring the unity of the methodology for its adaptation and use [1].

The study of management and administration as science begins with the study of their characteristics, first, historical, and then functional (special) ones. The essence of these concepts is distinguished in this article, indicating thus that the diversity of opinion has predetermined the understanding of management as the impact of a subject of management on the managed object, as well as the concept of management as the administration of socio-economic systems. The article contemplates the issues of historically established traditional and modern views on theoretical and applied aspects of management. The author pays special attention to the comprehensive comparison of the universal process and systems approaches to management cycles engineering and implementation. The author illustrated his observations and theoretical conclusions with two practical examples: the wellknown Deming cycle (PDCA), and an example of a complex of management tasks distributed by function within the framework of a management cycle. Particular attention is paid to the relationship between management as the economic category and processes of a state-level and intra-corporate nature.

It is essential to understand, however, that the formation and development of a modern economy are impossible without attention to domestic and foreign policy aspects. While describing an organization or processes occurring within it, one 
should not only analyze and evaluate subject-object relationships but also research the influence of micro-, meso- and macro-factors. Also, the legal prerequisites of these processes are vital, as they contribute to the construction of a high-quality system of planning and implementation of management decisions. Addressing the issues of administrative thought and modern management practice, the author stresses the necessity to pay special attention to administrative cycles. In his opinion, the frequently used current understanding of the role and significance of this concept does not fully and correctly reflect the essential characteristic of the idea of the "management cycle". The identicalness of the concepts of "administrative cycle" and "management cycle" is questionable, since the two proposed concepts are characterized in theory by different tasks and may in practice include different processes.

The key findings obtained as a result of the study include the definition of the most appropriate, in the opinion of the author, interpretation of a management cycle. This definition interprets the management cycle as a sequence of stages that reflect the main administrative, structural, organizational, and technological changes, as well as characterizes the state of administrative machinery and internal relations, contributing to the strategy implementation in a given socio-economic situation.

\section{Literature Review}

Modern opinions and theoretical concepts comprising the formation of innovative approach to management determine the unique role of methodological and technological tools as the basis of modern management. Many researchers developed the systems approach to management, focusing on the basic cycle and management algorithms according to the general control theory [2], [3]. Previously, the functional approach was dominant in management, based on a qualitative system of planning, control, and other functions; however, nowadays, research is paying attention to its shortcomings and gives priority to different approaches [4]. At the same time, there is also a widespread opinion which argues that the opposition toward functional and process approaches to management is fundamentally incorrect, since functions and processes as equisignificant concepts of managerial activity can exist only in close connection with each other [5].

The functional representation of management cycles in a format of periodically repeating the sequence of elaboration and implementation of targeted impact necessitates formulation and application of the process approach. It is a result of the studies of management genesis, which reveal its process-based nature, the sequence of formation, and the phased development of the functions pertaining to periodically repeating cycles of targeted impact [6].

A variety of objects, subjects, resources and other factors within the functional organization of the targeted impact precondition the development and application of a fairly wide range of modifications of the process approach to research and engineering of management cycles. It means that organizations need to adapt quickly and efficiently to changing environmental conditions by effectively managing their knowledge potential [7].

Information for enterprise resource and product life cycle management systems actively transform into a global strategy of integrated business processes' automation [8]. The specialized programs reduce the processing information and help managers to see the tasks fulfilment by the staff and the mistakes occurrence. The mobile access allows following the whole process of the company control from any part of the world using the internet connection that is very useful and necessary if a company has the affiliates in the different regions.

\section{Methodology}

The methodological bases of this publication are the principles of integrated approach and consistency. Both the general scientific method and specific economic research were applied during the study. The main contribution belongs to scientific abstraction, which facilitated the separation a number of secondary minor features that are neither essential nor constant, from the key problem of the essence and role of management cycles.

In turn, this made it possible to comprehensively analyze the issue from different perspectives, highlight the process and systems approaches to building management cycles, compare them, and juxtapose various options for existing cycles. The existing literature on this issue has been analyzed, and content from different sources has been synthesized. The research results are formulated using the method of generalization of theoretical conclusions.

\section{Key Results and Discussion}

\subsection{Comparison of the Process and Systems Approaches}

The cyclical nature of management that determines the basic format of its presentation is characterized by a periodically repeating sequence of actions that provides constructiveness of research and the 
appropriateness of management forecasting [9]. These positions constitute the basis for the development and application of predictive modification of the process-based approach to research and engineering of management cycles, which provides, in turn, an adequate representation of the most likely sequence of reliably expected stages of their engineering. In practice, it is especially important that the use of a predictive modification permits limiting the development of the destructive engineering of management cycles.

Processes that various organizations are used to realize their goals entail series of interrelated (or interacting) actions aimed at achieving the desired results. The process approach involves processes building in an organization to enable it to function as an integrated and complete system. Moreover, any management system integrates processes and measures aimed at achieving goals, while processes determine interrelated actions and checks to ensure the intended results. Depending on the context of the organization, detailed planning and control can also be defined and documented as necessary [10].

The assessment of the authenticity of threats related to deformation and the difficulty of amending the consequences of a destructive development of management cycles necessitates the development and application of project modifications to the process approach in order to research and cycle engineering. Its adaptation and use make it possible to preventively exclude the vast majority of destructive scenarios within development of management cycles, ensuring preconditions for programming an ever-increasing range of the latter. Since the 1960s, these features have been in demand and applied in the information support digitalization programs, formally used in the design of management process cycles, thus ensuring prerequisites for formulation and solution of automation problems.

The relevance of these capabilities and demand for them permit guaranteeing the universality of engineering and the adequacy of the use of a procedural modification of the process approach to research and management cycles engineering. Representation of a cycle by a procedure of periodically repeating sequences is traditionally the most common format for reflecting any process, including the management processes. At the same time, such a format of the process representation gets a new development in research and management engineering, based on the application of the "cycle in cycle" configurations known from programming. These are the base for engineering models that are most accurately characterized by the "management of control process" definitions and by its configuration engineering. Adaptation and use of the procedural modification of research, design, and engineering of management cycles also permit to create a database necessary for the development and application of specific methods used in programming strategies for the development of management processes.

The continuing progress in which procedures' decomposition pertaining to management cycles organizing makes it expedient to develop and use an operational modification of the process approach to research and engineering of management cycles. Its demand reflects the need to establish the components of a periodically repeating sequence of management cycle organization, transition conditions, and intermediate results that unite them into a single combination. Research of its communications with the help of the operational modification makes it possible to establish both real and potential capabilities of internal and external cooperation of the components. The decomposition of deconvolution process engineering formats in the management cycle research, ensured by its use, preconditions consistent presentation of their compositions and contents by distinguishing phases, stages, operations and actions as elements of design and implementation of cycles.

The application of various modifications of the process approach to research and engineering of management cycles, clearly reveal the essential dissimilarities of this approach, neglected by many researchers and empirics [11]. To mobilize and use the above advantages, one should assess fundamental differences in the formulation and application of systems and process approaches as key priorities in the study of management cycles.

This analysis has highlighted that significant differences have been clearly manifested throughout the comparison of the above representations. They consist in the fact that the sequence of component management cycles is prioritized while applying the process approach. Structures, classifications, and forms that support the implementation of these cycles expectedly remain the results of systems research and development. These conclusions should be projected onto the applied understanding of the fact that in real conditions, the content of the impact is most commonly perceived by the management cycle procedure description, which enables achievement of a specific result in the form of a system, form or composition.

In the course of planning and researching management cycles, it is necessary to continually take into account differences in the results of the formulation, use, presentation, and assessment of the adequacy of the process and systems approach to process-based engineering. From the standpoint of formulation and application of modifications regarding the process approach to the study of management cycles, the decision approved is being 
perceived as the dominant in the scope of organizational procedure and implementation a sequence of actions, in contrast to a format by which the formulation of the results is based on a system or its components. At the same time, it is mainly the management decision as a theoretical underpinning of the procedure for preparing, developing, and adopting a variant of the impact that is most adequately reflected in the model of a cycle, as well as of a method for developing and implementing a targeted impact.

In fundamental research and in real engineering of management cycles, it is extremely important to understand that, regardless of whether the cycle in question reflects a targeted effect on a system that is external in relation to the object, or it represents a new version of internal reorganization, it always defines an intellectually formed model of the targeted impact process cycle. Such an understanding highlights the possibilities of formulation and application of the process approach to scientific research, specialized training, and professional activities based on the analysis, development, and use of universal procedures for organizing management cycles.

The formulation and application of the above modifications of the process approach to the study and engineering of management cycles definitively determine, implement and modernize the structural representation of an organization on the basis of optimization the attachment and performance of the functions which are ensured, supported and carried out by them. In addition, innovative process-based studies of management cycles, which for a long time were empirical, are being equipped with the modifications considered above. Adaptive combination of those modifications is increasingly becoming the initial condition for ensuring the effectiveness of forecasting and designing of priority transformations and the prospective development of organizational structures, organizational changes, and their management. In real terms, this is expressed in the fact that each management procedure is considered by one of its most adequate definitions as a combination of key cycles conditioned by time and cooperation. By definition, the study of such interactions has to be formulated and applied in the first turn within the process approach that provides an adequate format for identifying, analysing, and representing management cycles.

The adaptation options for the aggregation and cooperation variations of the considered process approach modifications make it possible to represent its resource diversity and position it within a single logically verified research, training, and impact methodology in the field of management. Its feasibility demonstration, presentation, and positioning become an essential condition that directly mobilizes the adaptation of formulation and application of the process approach modifications to diversity study, engineering development, as well as to improvement and development of relations between the components of the targeted impact cycle. Differentiation, analysis, and presentation of the modifications considered above make it possible to propose the possibility and expediency of developing, as a dominant methodology idea, the research of the variety of process-oriented approaches that determine the priorities for the formulation and application of the management methodology as a whole.

Theoretical research in the management field indicates the need for an application of the process approach to management within lots of organizations operating in areas with particularly high competition. The example of educational institutions makes distinct the fact that this approach permits not only quality management of performance results, but also the more efficient use of the personnel, financial, material, technical and information capabilities of organizations [12].

Thus, the fundamental principles and results of the research, presented in this publication, make it possible to formulate the priority of the process approach and the adaptation of its key modifications spectrum, and this enables the author to proceed with the selection, analysis, and description of management cycles.

\subsection{Examples of Existing Management Cycles}

Management, as noted earlier, indicates in itself the presence of an impact reaction. This reaction also remains in the case of a transition from one stage of the life cycle of an enterprise or company to another. The question arises, then, whether the nature of this effect changes and whether this reaction remains, as before, an impact or it is transformed into any other reaction or state.

If we rely solely on a theoretical approach to understanding management cycles, then this concept is often identical to an administrative cycle [13], [14]. At the same time, in our opinion, they are not identical. So, for example, the PDCA cycle is shown in the following figure (Fig. 1), also known as the Deming cycle (otherwise, the Deming Wheel, or the Schewhart-Deming Cycle), is the most straightforward algorithm of manager's actions to manage the process and achieve its goals.

The Deming cycle in its most common nowadays version, with some subsequent changes, was proposed back in the 1950 s based on previous research (since 1939) of the implementation of scientific methods in the production process [15], 
[16]. At its core, it is a relatively universal and easyto-use system for describing a cycle of continuous improvements. Each of its phases requires different

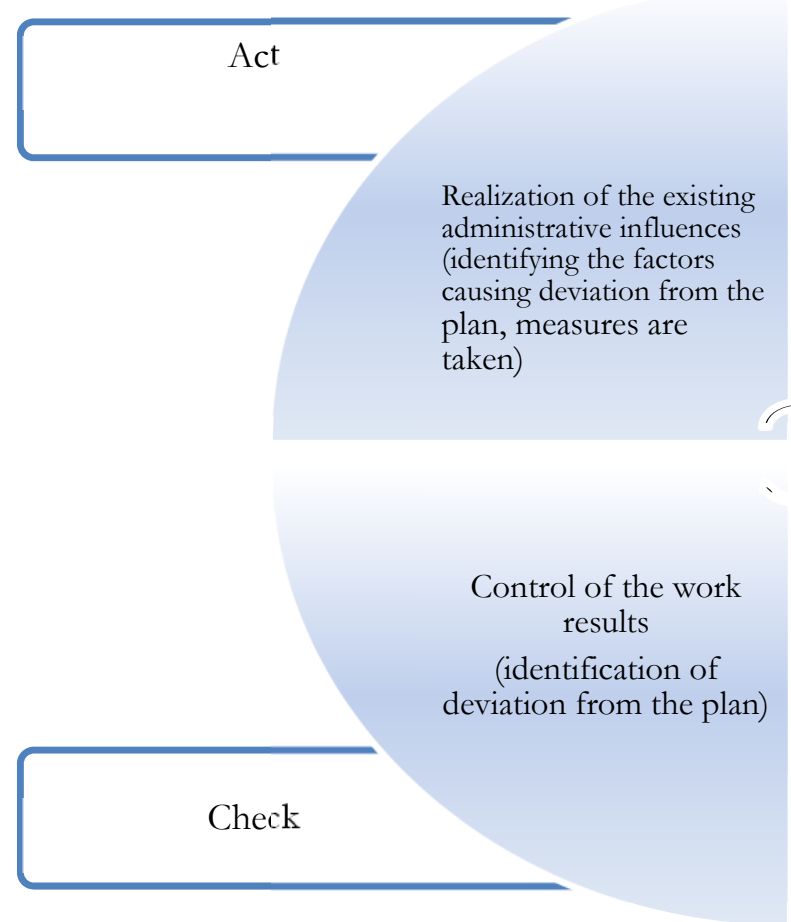

skills, depends on the success obtained at a previous stage, and also has its drawbacks [17], [18].

The management cycle begins with planning:

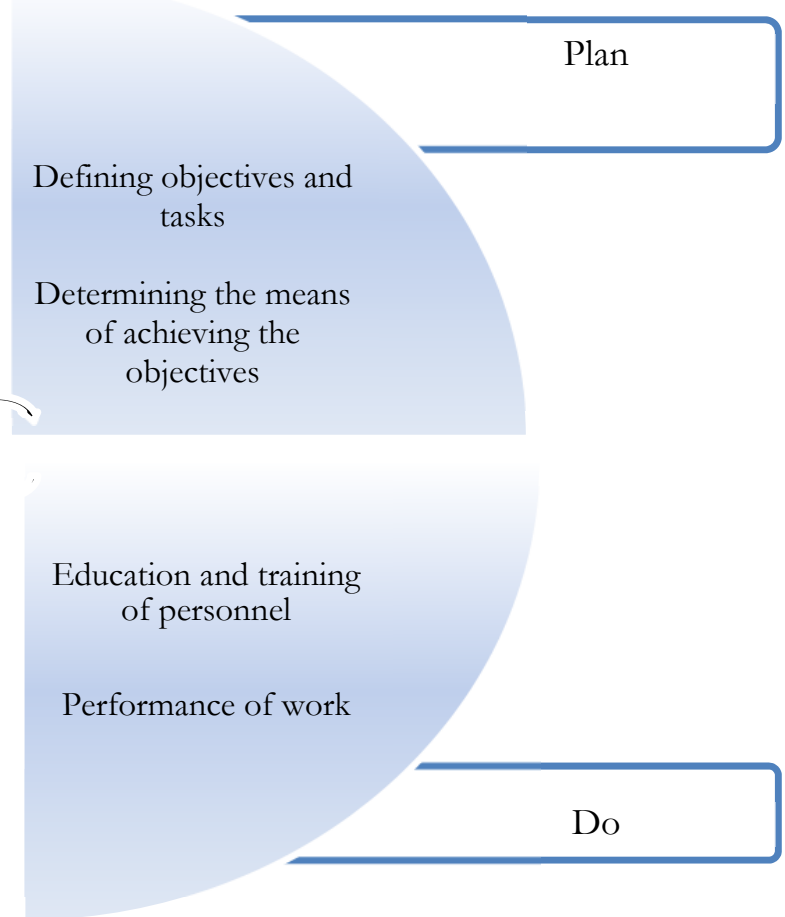

Figure 1. The Deming Cycle (PDCA). Source: own research

We can consider in more detail all four stages of this cycle:

Planning (Plan):

- setting goals and establishing processes in order to achieve goals;

- work planning in order to achieve the goals of the process and satisfy the customer;

- planning for the allocation and distribution of necessary resources.

- Execution (Do):

- performance of a planned work.

- Check:

- information collection and monitoring, on the basis of key performance indicators (KPI), of results obtained during the implementation of the process;

- identification and analysis of deviations, establishing the causes of deviations.

- Decision (Act - control, adjustment):

- taking measures to eliminate the causes of deviations from the planned result;

- changes in the planning and distribution of resources [19].

The range of application of the Deming cycle is reasonably wide. Various studies confirm that the use of the PDCA methodology leads to increased production efficiency in different sectors of the economy, for example, in agriculture, without any significant increase in capital investment [20]. This also applies to industry, namely, to small and medium-sized enterprises, where the implementation of the Deming cycle also allows realizing the principle of continuous improvement [16]. The PDCA cycle can be used in enhancing the environmental performance of industrial enterprises whose activities negatively affect the environment; in particular, it enables them to reduce waste and helps ensure environmental sustainability through effective environmental management in order to implement the principles of clean production [21], [22]. In addition, the application of this approach enables increasing the energy efficiency of production and achieving energy optimization by steadily reducing energy consumption [23]. The research shows successful results of using the PDCA cycle to solve issues in the tourism sector since there is no need to use additional software or complex mathematical calculations, while an opportunity is provided to identify a problem and determine ways to solve it [24]. Besides, the advantages of the process approach are especially visible within enterprises that operate in high competition markets requiring a frequent change in business processes [25]. We would like to give one more example that reflects the variety of management tasks within the framework of the management cycle shown in Fig. 2: 


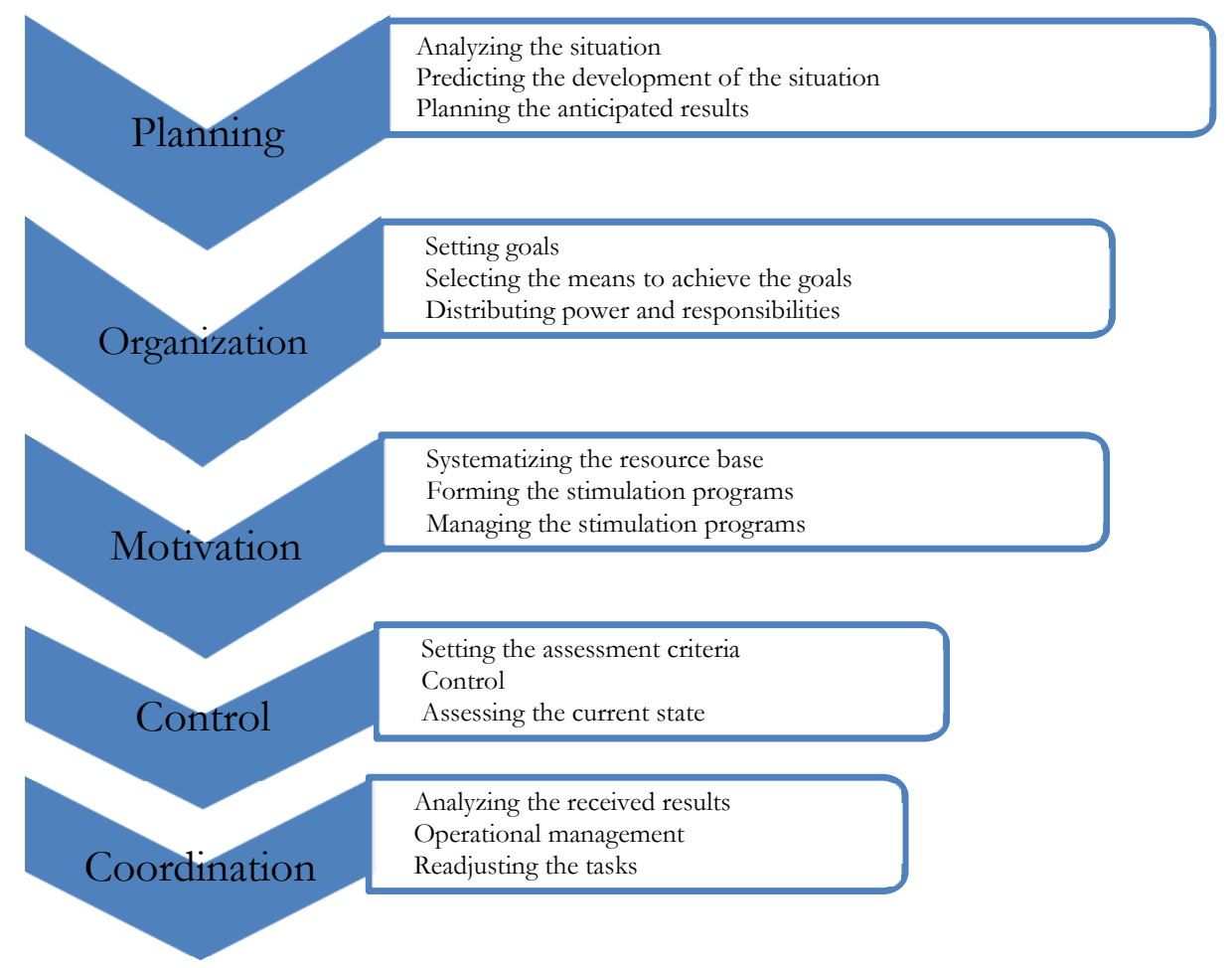

Figure 2. A variety of management tasks distributed by function

These tasks are grouped according to key management functions in the framework of which they are performed [26]. It should be noted that such a distinction is rather arbitrary since all these functions are interconnected, and each of them is organically present in other management functions [27]. Thus, the first conclusion can be made, and it reads as follows: application of the essence and meaning of the management cycle in such context is justified as it provides rationalization for, inter alia, the business processes of companies, however, it is the opposite with regards to applying of the similar understanding within the scale of micro- and macroprocesses in a state. In general, the range of tools and methodology for continuous improvement of business processes is quite wide (it also includes the approaches of DMAIC, Design for Six Sigma, Radar Matrix and others), so their choice and subsequent implementation may vary depending on a particular organization or enterprise and its productivity enhancement needs [28].

\subsection{Definition of the Essence of the Management Cycle}

Even though the fast majority of researchers focus on the cyclical nature of the management process, they imply different senses to the very concept of "management cycle", including various components and actions with different sequences in the cycle. Therefore, the notions of management cycle and its structure differ through various pieces of research, which is also related to differences in the formulations regarding the essence of management [29]. In this regard, in the author's opinion, it is advisable to consider management cycle as a separate or special general economic concept, which content should primarily include the following criteria:

- time or duration;

- assessment of the objectivity of conditions;

- nature of ownership;

- level of development of the manufacturing, industrial, business and other sectors;

- trends of the economy;

- global quality standards;

- political and legal aspects;

- willingness to change, from the point of view of the state and business;

- identifying priorities that contribute to transition to a competitive level, etc.

Management cycle engineering makes it possible to clearly identify the composition, sequence and conditions concerning the succession of stages; however, it also largely determines the aims for differentiation and the specific content of each of them. Thus, the essence of each differentiated component of the management cycle is determined, which makes it possible to uniquely identify, comprehensively classify, sequentially engineer, meaningfully orient and purposefully coordinate its implementation. At the same time, the detailing and determination of this sequence identifies as a whole the general configuration of engineering with respect to the basic organization management procedure as a 
firmly established and periodically repeating the cycle of purposeful actions.

Such actions, combined into professional operations, ensure the targeted formation and consistent implementation of the corresponding functional cycle stages in the scope of managing production process and management units. Effective implementation of these stages makes it possible to obtain specific intermediate results that differentiate the stages, which, in their turn, are consecutively shaped into research phases and the phases of the impact on the ongoing process cycle of setting and achieving goals [30]. The Deming cycle, for example, is iterative and can be repeated several times if necessary, in the process of implementing typical quality enhancement projects, being, at the same time, well adapted for practical training [31]. Thus, a periodically repeating sequence of cycles creates a single process that forms the overall activity of the organization's management, and it is closely intertwined with other procedures that are managed in parallel and sequentially.

It is important to understand that such a procedural representation ensures that any real management cycle is being brought back to an already occurred, expected and understandable sequence of actions. Common examples of such an approach can be typical, regular, or analog cycles of development, adoption, and implementation of decisions in a wide variety concerning the modifications of a situation, which is basic for each of them. Precisely they served previously as the basis for the development, engineering and application of the first automated control systems based on programming and implementation of the "management cycle management" model. Later on, this approach made it possible to automate the vast majority of routine control system procedures based on modern information technologies, and nowadays, it has become an appropriate foundation for the development and implementation of digitalization programs for the economy and management.

\section{Conclusion}

The author considers it appropriate to use the following interpretation of the management cycle.

The management cycle is a cumulative sequence of stages that reflect key administrative, structural, organizational, and technological changes that characterize the state of the administrative machinery and relations within the system that contribute to strategy implementation in given socio-economic conditions.
This aspect (purely theoretical, at first glance) is of a very important applied value since it is realized through the activity of many functional subsystems of enterprises, organizations and companies whose tasks include researching the issues of micro- and macro-nature. In connection with the aboveconsidered features pertaining to the framework of research categories and concepts as well as with a designation of some problem areas that impede the development of modern management in full, the following conclusion can be formulated. The range of tasks to be solved should be complex and multidimensional in nature, and, forming a management cycle, should aim at achieving designated goal or goals, with due regard for the attention towards dynamic and often uncertain conditions in both business- and macro-environments.

\section{References}

[1]. Latfullin, G. A. \& Raichenko, A. D. (2019). Metodologija upravlenija: uchebnik dlja vuzov [Methodology of Management: A Textbook for Universities]. St. Petersburg: Peter. ISBN: 978-54461-1036-0

[2]. Allen, W. R. (2000). The Basic Management Cycle: A Systems Approach to the Management Process. In: Proceedings of the International Conference on Systems Thinking in Management. Geelong: CEUR, pp. 38-43. Retrieved from: http://ceur-ws.org/Vol72/003\%20Allen\%20Cycle.pdf [Accessed $04 \mathrm{Feb}$, 2020].

[3]. Vlasenko, M. N., Potekhetsky, S. V. \& Unizhayev, N. V. (2016). Sistemnyy podhod k upravleniju slozhnymi protsessami [A systems approach to managing complex processes]. Territory of Science, 4, 75-80.

[4]. Abdulrahaman, S. F., Yahaya, I. \& Kabir, H. D. (2013). Operational approach, functional approach, and development of management in the 21 st century. African Multidisciplinary Journal, 1(1), 81-98.

[5]. Lyandau, Y. V. \& Stasevich, D. I. (2014). Teorija protsessnogo upravlenija [Theory of process management]. Moscow: INFRA-M. ISBN: 978-516-006400-0.

[6]. Lyandau, Yu. V. (2013). Istorija razvitija protsessnogo podhoda $\mathrm{k}$ upravleniju [The development of the process-based approach to management]. Statistics and Economics, 6, 65-68.

[7]. Raudeliūnienè, J., Davidavičienè, V. \& Jakubavičius, A. (2018). Knowledge management process model, Entrepreneurship and Sustainability Issues, 5(3), 542-554. https://doi.org/10.9770/jesi.2018.5.3(10)

[8]. Batkovskiy, A. M., Kurennykh, A. E., Semenova, E. G., Sudakov, V. A., Fomina, A. V. \& Balashov, V. M. (2019). Sustainable project management for multi-agent development of enterprise information systems. Entrepreneurship and Sustainability Issues, 7(1), 278-290.

http://doi.org/10.9770/jesi.2019.7.1(21) 
[9]. Afanasyev, V. Y. \& Raichenko, A. V. (2013). Zakonomernost' tsiklichnosti $\mathrm{V}$ printsipah upravlenija [The pattern of cyclicity in the principles of management]. Vestnik Universiteta, The State Iniversity of Management, 16, 188-193.

[10]. International Organization for Standardization (n.d.). The Process Approach in ISO 9001:2015.

Retrieved from:

https://www.iso.org/files/live/sites/isoorg/files/archiv e/pdf/en/iso9001-2015-process-appr.pdf.

[Accessed: 12 January, 2020]

[11]. Grishko, L. A., \& Seraya, N. N. (2018). The process approach in modern management practice. Innovative Economy: Prospects for Development and Improvement, 1(7), 33.

[12]. Levina, E. Y., Kamasheva, Y. L., Gazizova, F. S., Garayeva, A. K., Salpykova, I. M., Yusupova, G. F., \& Kuzmin, N. V. (2015). A process approach to management of an educational organization. Rev. Eur. Stud., 7, 234-240.

http://doi.org/10.5539/res.v7n4p234

[13]. Novikov, D. A. (2011). Mehanizmy upravlenija: Uchebnoje posobie [The Mechanisms of Management: Tutorial]. Moscow: URSS. ISBN: 978-5-9710-0342-7

[14]. Udalov, F. E., Alyokhina, O. F. \& Gaponova, O. S. (2013). Osnovy menedzhmenta [Fundamentals of Management: Tutorial]. Nizhny Novgorod: State University of Nizhny Novgorod.

[15]. Moen R (2009) Foundation and history of the PDSA Cycle. In: Asian network for quality conference. Tokyo. Retrieved from:

https://deming.org/uploads/paper/PDSA_History_Ro n Moen.pdf [Accessed: 28 Jan, 2020].

[16]. Moen, R. D., \& Norman, C. L. (2010). Circling back. Quality Progress, 43(11), 22-28.

[17]. Jalkio, J. \& Weimerskirch, A. (2008). Using the Deming Cycle for Continuous Improvement in Engineering Education. In: ASEE Annual Conference \& Exposition. Pittsburgh: ASEE.

[18]. Jagusiak-Kocik, M. (2017). PDCA cycle as a part of continuous improvement in the production company - a case study. Production Engineering Archives, 14, 19-22. http://doi.org/10.30657/pea.2017.14.05.

[19]. Repin, V., \& Elyferov, V. (2013). Protsessnyy podkhod $\mathrm{k}$ upravleniyu. Modelirovanie biznesprotsessov [Process approach to management. Modeling of business processes]. Moscow: Mann, Ivanov i Ferber. ISBN: 978-5-91657-554-5

[20]. Kholif, A. M., Abou El Hassan, D. S., Khorshid, M. A., Elsherpieny, E. A. \& Olafadehan, O. A. (2018). Implementation of model for improvement (PDCA-cycle) in dairy laboratories. Journal of Food Safety, 38(3), 1-6. http://doi.org/10.1111/jfs.12451
[21]. Silva, A. S., Medeiros, C. F. \& Viera, R. K. (2017). Cleaner Production and PDCA cycle: Practical application for reducing the Cans Loss Index in a beverage company. Journal of Cleaner Production, 150, 324-338. http://doi.org/10.1016/j.jclepro.2017.03.033

[22]. Garza-Reyes, J. A., Romero, J. T., Govindan, K., Cherrafi, A. \& Ramanathan, U. (2018). A PDCAbased approach to Environmental Value Stream Mapping (EVSM). Journal of Cleaner Production, 180, 335-348. http://doi.org/10.1016/j.jclepro.2018.01.121

[23]. Prashar, A. (2017). Adopting PDCA (Plan-DoCheck-Act) cycle for energy optimization in energyintensive SMEs. Journal of Cleaner Production, 145, 277-293. http://doi.org/10.1016/j.jclepro.2017.01.068

[24]. Kupchinskaia, Iu. A. \& Chekhovskaia, S. A. (2016). Osnovy upravlenija kachestvom: tsikl PDCA [Basis of Quality Management: PDCA Cycle]. Business education in the knowledge economy, 3(5), 36-39.

[25]. Trubitsina, K. A. \& Ageev, A. V. (2015). Upravlenije organisatsiej: funktsionalnyy i protsessnyy podhody [Organization Management: Functional and process approaches]. VII International Student Scientific Conference "Student Scientific Forum - 2015".

[26]. Kornienko, E. V. \& Shindina, L. D. (2015). Teorija upravlenija: uchebnoje posobie [Management Theory: Tutorial]. Taganrog: Stupin S.A. ISBN: 978-5-9906281-0-6

[27]. Pudovkina, N. G. (2011). Funktsija analiza v upravlencheskov tsikle [Analysis function in the management cycle]. Science Vector of Togliatti State University Series: Pedagogy, Psychology, 2(5), 167170.

[28]. Sokovic, M., Pavletic, D. \& Kern Pipan, K. (2010). Quality Improvement Methodologies - PDCA Cycle, RADAR Matrix, DMAIC and DFSS. Journal of Achievements in Materials and Manufacturing Engineering, 43(1), 476-483.

[29]. Atrashenko, A. N. (2006). Analiz struktury upravlencheskogo tsikla [Analysis of the management cycle structure]. Tomsk State Pedagogical University Bulletin. Series: Pedagogy, 10(61), 108-111.

[30]. Ljalin, A. M. (2009). Teorija menedzhmenta [Theory of Management]. St. Petersburg: Peter (in Russian). ISBN 978-5-49807-523-5

[31]. Berman, L., Raval, M. V., \& Goldin, A. (2018, December). Process improvement strategies: Designing and implementing quality improvement research. In Seminars in pediatric surgery (Vol. 27, No. 6, pp. 379-385). WB Saunders. http://doi.org/10.1053/j.sempedsurg.2018.10.006 . 